
e Gampsonyx swainsonii (Accipitridae). PUBVET, Londrina, V. 6, N. 11, Ed. 198, Art. 1327, 2012.

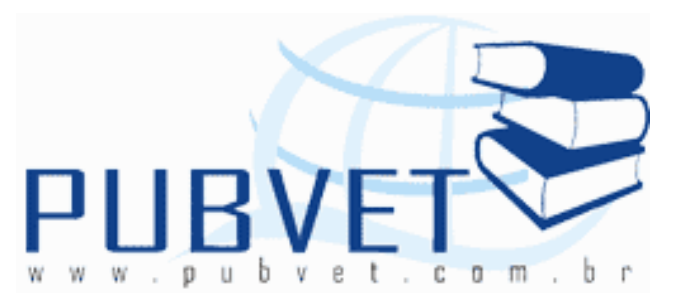

PUBVET, Publicações em Medicina Veterinária e Zootecnia.

\title{
Estudo anatomotopográfico do tubo digestório de Heterospizias meridionalis e Gampsonyx swainsonii (Accipitridae)
}

\footnotetext{
André Luiz Quagliatto Santos ${ }^{1}$, Mariana Batista Andrade ${ }^{3}$, Árthur Paulino Sanzo Kaminishi ${ }^{2}$, Caio Henrique Ferreira ${ }^{2}$, Rogério Rodrigues de Souza ${ }^{2}$, Lorena Tannús Menezes², Sérgio Rodrigo Pereira de Oliveira², Liliane Rangel Nascimento², Flávio Machado de Moraes ${ }^{1}$
}

Laboratório de Ensino e Pesquisa em Animais Silvestres - LAPAS, FAMEV/UFU, email: quagliatto@famev.ufu.br 1. Docente. 2. Mestrandos. 3. Doutoranda.

\section{Resumo}

Dentre as mais de 1600 espécies de aves encontradas no Brasil, inúmeras vem sendo criadas como animais de estimação ou mantidas em cativeiro, seja em zoológicos ou criatórios conservacionistas, fato que desperta a necessidade por maiores conhecimentos de ordem anatômica e fisiológica nestes animais. O aparelho digestório é o "compartimento" do organismo responsável pela manutenção da vida, sendo o tubo digestório de cada ave adaptado para processar e utilizar o mais eficientemente possível o alimento disponível em seu habitat. Com o intuito de se ampliar os conhecimentos anatômicos relativos ao tubo digestório das aves, abordou-se em um estudo anatomotopográfico, dois exemplares de aves, Gampsonyx swainsonii e Heterospizias meridionalis, 
SANTOS, A.L.Q. et al. Estudo anatomotopográfico do tubo digestório de Heterospizias meridionalis e Gampsonyx swainsonii (Accipitridae). PUBVET, Londrina, V. 6, N. 11, Ed. 198, Art. 1327, 2012.

representantes da ordem Accipitriformes, doadas pelo IBAMA- Uberlândia/MG. No Laboratório de Pesquisa em Animais Silvestres (LAPAS) da UFU as aves foram fotografadas, identificadas quanto à espécie e dissecadas, com a finalidade de se obter informações relativas à topografia, forma e dimensões dos segmentos do tubo digestório. O tubo digestório dos exemplares estudados apresentou poucas variações topográficas e Gampsonyx swainsonii não possui ceco, o que foi observado em Heterospizias meridionalis.

Palavras-chave: gavião, esôfago, estômago, intestino.

\title{
Anatomical study of the digestive tract of Heterospizias meridionalis e Gampsonyx swainsonii (Accipitridae)
}

\begin{abstract}
Among the more than 1600 bird species found in Brazil, many are being raised as pets or kept in captivity, whether in zoos or farms conservationists, a fact which raises the need for more knowledge of anatomical and physiological order in these animals. The digestive system is the "box" of the body responsible for the maintenance of life, and the digestive tract of each bird adapted to process and use as efficiently as possible the food available in their habitat. In order to increase their knowledge regarding the anatomical digestive tract of birds, we dealt with in a study anatomotopographic, two specimens of birds, Gampsonyx swainsonii and Heterospizias meridionalis, representatives of the order Accipitriformes, donated by IBAMA, Uberlândia / MG. In the Laboratory Teaching and Research in Wildlife (LAPAS) UFU, the birds were photographed and identified as to species and dissected for the purpose of obtaining information on topography, form and dimensions of the segments of the digestive tract. The digestive tract of the specimens studied showed little topographical variations and
\end{abstract}


SANTOS, A.L.Q. et al. Estudo anatomotopográfico do tubo digestório de Heterospizias meridionalis e Gampsonyx swainsonii (Accipitridae). PUBVET, Londrina, V. 6, N. 11, Ed. 198, Art. 1327, 2012.

Gampsonyx swainsonii has no cecum, which was observed in Heterospizias meridionalis.

Keywords: hawk, esophagus, stomach, intestine.

\section{INTRODUÇÃO}

A avifauna mundial apresenta uma riqueza fantástica, sendo reconhecidas cerca de 9.700 espécies em todo o mundo (29 ordens, 187 famílias e mais de 2.000 gêneros). No Brasil são encontradas mais de 1.600 espécies (MARÇAL Jr.; FRANCHIN, 2003), das quais inúmeras são criadas em cativeiro, na maioria das vezes sem finalidade econômica (MAPELI, 2003).

Algumas de suas funções mais importantes na natureza estão relacionadas ao comportamento alimentar, como o controle de pragas e ratos em diversas áreas, polinização de flores e disseminação de sementes (ANDRADE, 1997), já que quase todos os tipos de animais ou vegetais são aproveitados por alguma ave (PETERSON et al., 1971).

O aparelho digestório é o "compartimento" do organismo responsável pela manutenção da vida (MACARI; FURLAN; NAKAGHI, 1994), sendo o tubo digestório de cada ave adaptado para processar e utilizar o mais eficientemente possível o alimento disponível em seu habitat (DUKE, 1996; POUGH; HEISER; McFARLAND, 1999). Essa capacidade evolutiva permitiu a sobrevivência das diversas populações de aves atuais, que criaram seus nichos ecológicos próprios de acordo com os recursos alimentares disponíveis (PETERSON et al., 1971).

O conhecimento de particularidades anatômicas do tubo digestório das diferentes espécies é imprescindível na interpretação correta e completa das imagens radiográficas de uma ave (SMITH; SMITH, 1997), bem como na execução de procedimentos de rotina e intervenções cirúrgicas. Representa um fator determinante na nutrição adequada principalmente de aves mantidas em cativeiro ou como animais de companhia. 
SANTOS, A.L.Q. et al. Estudo anatomotopográfico do tubo digestório de Heterospizias meridionalis e Gampsonyx swainsonii (Accipitridae). PUBVET, Londrina, V. 6, N. 11, Ed. 198, Art. 1327, 2012.

A escassez de informações relevantes sobre a anatomia do tubo digestivo de aves ornamentais é preocupante, considerando-se que algumas das doenças importantes atualmente relatadas nestes animais tem origem no trato gastrointestinal (FLORES, et al., 2005; RODENBUSH, et al., 2004; BARTON; HOUSTON, 2001; LEMOS, et al., 1999).

Logo, propôs-se realizar uma descrição anatômica do tubo digestório de dois aves da ordem Accipitriformes, enfocando as principais características topográficas e particularidades anatômicas dos espécimes.

\section{MATERIAL E MÉTODOS}

Este estudo foi realizado utilizando-se duas espécies de aves representantes da ordem Accipitriformes doados pelo IBAMA - Uberlândia-MG para o Laboratório de Pesquisa em Animais Silvestres (LAPAS) da Faculdade de Medicina Veterinária da Universidade Federal de Uberlândia onde foram fotografados, de modo a enfatizar aspectos individuais que diferenciam as espécies.

A identificação das aves incluiu sua classificação quanto à ordem, família, gênero e espécie e foi realizada com auxílio da Lista das aves do Brasil (2011), Accioly (2000), Souza (1998) e Juniper e Pan (1998).

As duas espécies representantes da ordem Accipitriformes estudadas foram Heterospizias meridionalis (gavião-caboclo) e Gampsonyx swainsonii (gaviãozinho) (Figuras 01 e 02).

Cada exemplar, depois de submetido ao processo completo de dissecação e registro das informações relevantes, foi conservado em solução de formaldeído a $10 \%$ injetada em toda a musculatura das aves com seringas descartáveis de 10 $\mathrm{ml}$ e agulha descartável de $13 \times 0,45 \mathrm{~mm}$.

Foram dissecadas a fresco, com a finalidade de manter os órgãos em suas dimensões originais, obtendo-se medidas de comprimento e diâmetro com mínima margem de erro. Concomitantemente, procedeu-se à descrição e 
SANTOS, A.L.Q. et al. Estudo anatomotopográfico do tubo digestório de Heterospizias meridionalis e Gampsonyx swainsonii (Accipitridae). PUBVET, Londrina, V. 6, N. 11, Ed. 198, Art. 1327, 2012.

elaboração de desenhos esquemáticos e fotografias enfocando características relativas a dimensionamento, topografia, morfologia e composição do tubo digestivo.

O comprimento total de cada ave, que consiste na distância entre a extremidade rostral do bico até a extremidade caudal da última pena da cauda, foi obtido com o animal em decúbito dorsal e com o pescoço estendido. O gaviãocaboclo (Heterospizias meridionali), fêmea, apresentou $52 \mathrm{~cm}$ de comprimento, e - gaviãozinho (Gampsonyx swainsonii), macho, apresentou $22,4 \mathrm{~cm}$ de comprimento.

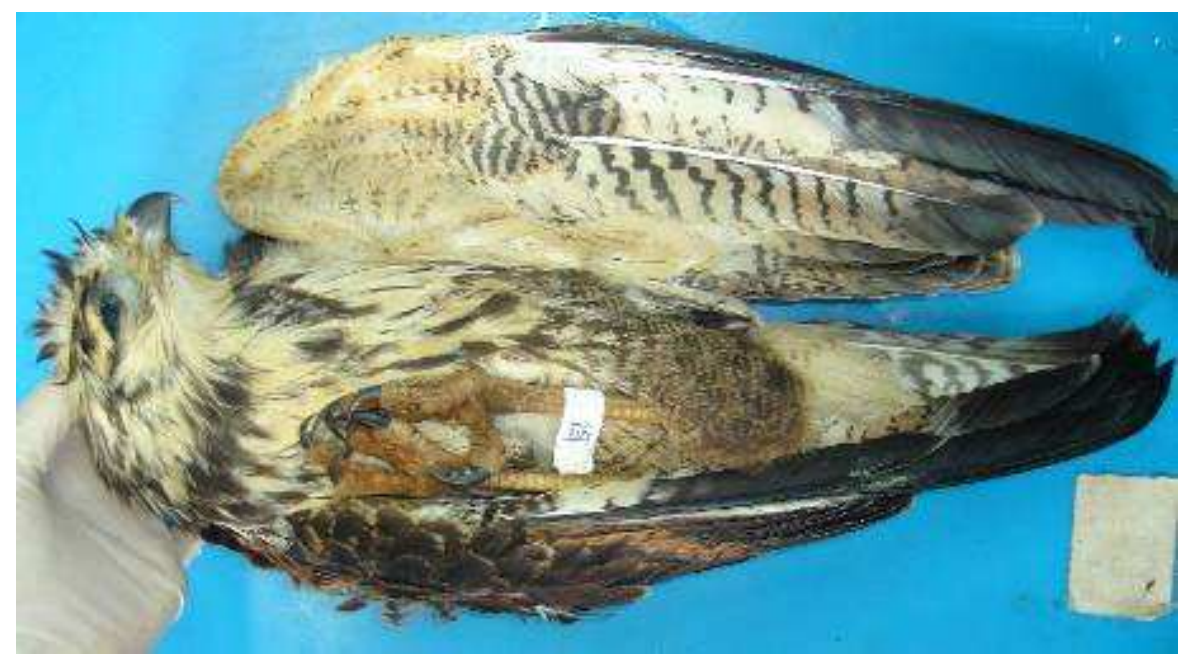

Figura 01: gavião-caboclo, Heterospizias meridionalis Latharn, 1790 (ACCIPITRIDAE) 
SANTOS, A.L.Q. et al. Estudo anatomotopográfico do tubo digestório de Heterospizias meridionalis e Gampsonyx swainsonii (Accipitridae). PUBVET, Londrina, V. 6, N. 11, Ed. 198, Art. 1327, 2012.

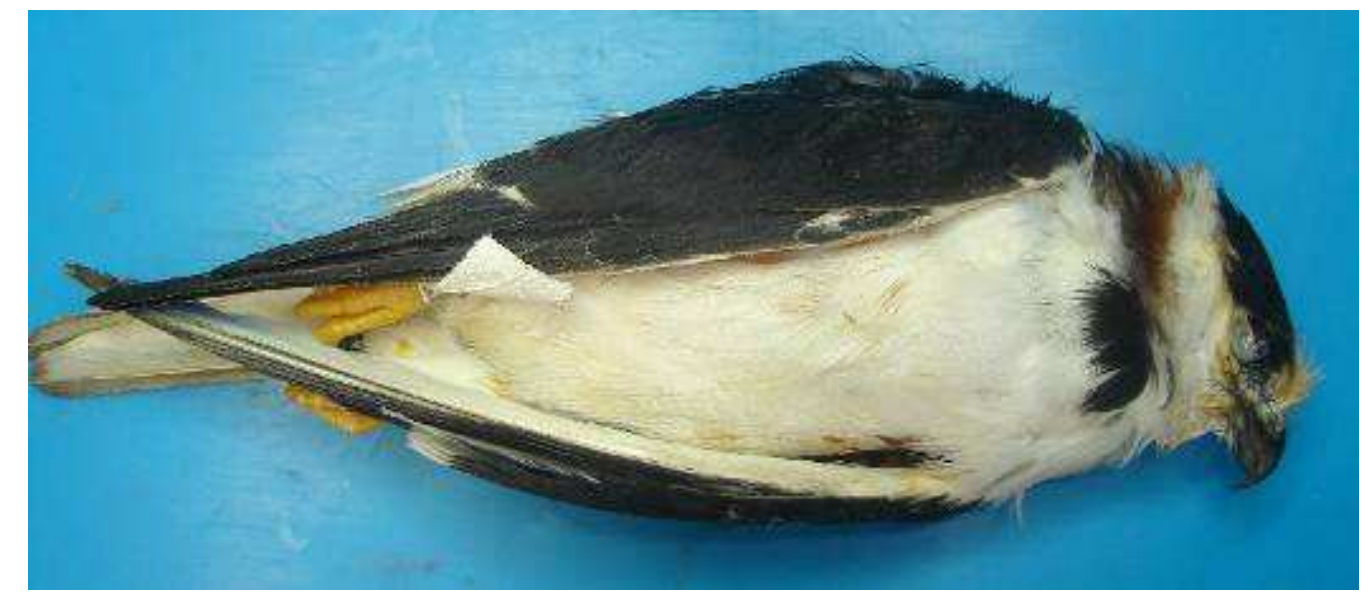

Figura 02: Gaviãozinho, Gampsonyx swainsonii Vigors, 1825 (ACCIPITRIDAE)

Com o auxílio de um cabo de bisturi no 4, uma lâmina para bisturi no 23, uma pinça Adson e uma pinça anatômica, procedeu-se a abertura da cavidade celomática de cada exemplar a partir de uma incisão na linha mediana ventral (delimitada pelo osso esterno e cloaca) e posterior retirada da quilha.

Foram adotados os seguintes pontos de referência para descrição anatômica e mensuração dos segmentos do tubo digestivo:

- Esôfago cervical: início na laringe e término na entrada da cavidade celomática;

- Inglúvio: início na região de dilatação do esôfago cervical e término na extremidade cranial do esôfago torácico;

- Esôfago torácico: início na entrada da cavidade celomática e término na junção com o proventrículo;

- Proventrículo: início na união com esôfago torácico e término na divisão com o ventrículo ou no istmo, quando presente;

- Ventrículo: início na união com o proventrículo e término no início da alça descendente do duodeno; 
SANTOS, A.L.Q. et al. Estudo anatomotopográfico do tubo digestório de Heterospizias meridionalis e Gampsonyx swainsonii (Accipitridae). PUBVET, Londrina, V. 6, N. 11, Ed. 198, Art. 1327, 2012.

- Alça descendente do duodeno: início no piloro e término na curvatura de união com a alça ascendente do duodeno;

- Alça ascendente do duodeno: início na união com a alça anterior e término na curvatura de união ao segmento jejunoilíaco;

- Jejuno-íleo: início na união com o segmento anterior e término na divisão com coloreto, considerando-se a presença de cecos, quando existirem;

- Ceco(s): do seu ponto de inserção no segmento intestinal ao seu ápice;

- Coloreto: início na base do(s) ceco(s), quando existirem ou do momento em que se desfazem as alças que compõem o segmento jejunoilíaco e término na cloaca;

Após descrição topográfica, o tubo digestivo foi individualizado com o auxílio de uma pinça anatômica, uma pinça hemostática, uma pinça dente de rato, uma tesoura Mayo curva e uma tesoura Metzembaum reta, divulsionando-se os tecidos que mantinham os segmentos do tubo digestivo relacionado a outros órgãos.

Cada órgão foi mensurado com um paquímetro Starret de precisão 0,05 $\mathrm{mm}$, de modo a registrar o comprimento e diâmetro dos mesmos. Estabeleceu-se uma relação, em porcentagem média, entre o comprimento de cada segmento do tubo digestivo e o comprimento total dos exemplares (Quadros 01 e 02). 
SANTOS, A.L.Q. et al. Estudo anatomotopográfico do tubo digestório de Heterospizias meridionalis e Gampsonyx swainsonii (Accipitridae). PUBVET, Londrina, V. 6, N. 11, Ed. 198, Art. 1327, 2012.

\section{RESULTADOS}

Quadro 01: Medidas de comprimento e diâmetro, dos órgãos do tubo digestivo de gaviãozinho.

\begin{tabular}{|l|c|c|}
\hline \multicolumn{1}{|c|}{ Órgão } & Comprimento $(\mathrm{mm})$ & Diâmetro $(\mathrm{mm})$ \\
\hline Esôfago cervical & 36,00 & 9,80 \\
\hline Esôfago torácico & 31,60 & 8,10 \\
\hline Inglúvio & 23,75 & 12,65 \\
\hline Proventrículo & 16,35 & 11,70 \\
\hline Ventrículo* & $17,85 \times 17,45 \times 3,45$ \\
\hline $\begin{array}{l}\text { Alça descendente do } \\
\text { duodeno }\end{array}$ & 29,70 & 4,30 \\
\hline $\begin{array}{l}\text { Alça ascendente do } \\
\text { duodeno }\end{array}$ & 35,55 & 5,70 \\
\hline Jejuno-íleo & 132,70 & 3,20 \\
\hline $\begin{array}{l}\text { Coloreto (Int. grosso) } \\
\text { * Comprimento X Largura X Espessura }\end{array}$ & 34,40 & 4,40 \\
\hline
\end{tabular}

Quadro 02: Medidas de comprimento e diâmetro, dos órgãos do tubo digestivo de gavião-caboclo.

\begin{tabular}{|l|c|c|}
\hline \multicolumn{1}{|c|}{ Órgão } & Comprimento $(\mathrm{mm})$ & Diâmetro $(\mathrm{mm})$ \\
\hline Esôfago cervical & 96,05 & 9,25 \\
\hline Esôfago torácico & 53,15 & 10,10 \\
\hline Inglúvio & 41,50 & 20,30 \\
\hline Proventrículo & 29,15 & 20,85 \\
\hline Ventrículo* & $26,80 \times 23,60 \times 20,00$ \\
\hline $\begin{array}{l}\text { Alça descendente do } \\
\text { duodeno }\end{array}$ & 56,55 & 7,30 \\
\hline $\begin{array}{l}\text { Alça ascendente do } \\
\text { duodeno }\end{array}$ & 58,70 & 6,15 \\
\hline Jejuno-íleo & 416,80 & 7,35 \\
\hline Ceco direito & 14,70 & 6,25 \\
\hline Ceco esquerdo & 13,10 & 6,30 \\
\hline Coloreto (Int. grosso) & 119,55 & 7,70 \\
\hline \multicolumn{2}{|l|}{ *Comprimento X Largura X Espessura } \\
\hline
\end{tabular}


SANTOS, A.L.Q. et al. Estudo anatomotopográfico do tubo digestório de Heterospizias meridionalis e Gampsonyx swainsonii (Accipitridae). PUBVET, Londrina, V. 6, N. 11, Ed. 198, Art. 1327, 2012.

O esôfago cervical se inicia dorsalmente a traquéia, na face ventral do pescoço, e logo em seu terço inicial desvia-se para o antímero direito, antagonicamente à traquéia, que se dirige ao antímero esquerdo, em gaviãozinho. Em gavião-caboclo a porção cervical se mantém dorsalmente à traquéia, no antímero direito do pescoço. É mais comprido que o segmento torácico, representando em média $17,43 \%$ do comprimento total das aves estudadas (Figura 05).

Em seu terço médio o esôfago cervical dilata-se formando o inglúvio, o qual possui formato de uma bolsa, está firmemente aderido à pele, projetado lateralmente e direcionado craniocaudalmente. Equivale em média, a 8,09\% do comprimento total dos representantes.

O esôfago torácico inicia-se ao nível do primeiro par de costelas e representa em média $11,70 \%$ do comprimento total das aves. Segue pela linha mediana da cavidade, dorsalmente à traquéia, siringe, bifurcação traqueal e coração e ventralmente aos lobos pulmonares, unindo-se ao proventrículo ao nível do terço proximal do lobo hepático esquerdo.

O estômago glandular é cilíndrico e situa-se no antímero esquerdo da cavidade. Em gaviãozinho localiza-se dorsalmente a metade cranial do lobo hepático esquerdo, ao passo que em gavião-caboclo mantém contato com toda a face dorsal do lobo. Dorsolateralmente relaciona-se lobo hepático direito e ventralmente à porção caudal do lobo pulmonar esquerdo. Equivale, em média, a $6,62 \%$ do comprimento total dos representantes.

O ventrículo inicia-se dorsalmente à metade caudal do lobo hepático esquerdo em gaviãozinho. A porção cranial de sua face ventrolateral direita situase dorsalmente à porção caudal do lobo hepático direito. Em gavião-caboclo não se relaciona ao lobo hepático esquerdo. Está situado ventralmente ao lobo renal cranial esquerdo e testículo (ovário na fêmea) e parte do jejuno-íleo. Representa, em média, $6,67 \%$ do comprimento total das aves. 
SANTOS, A.L.Q. et al. Estudo anatomotopográfico do tubo digestório de Heterospizias meridionalis e Gampsonyx swainsonii (Accipitridae). PUBVET, Londrina, V. 6, N. 11, Ed. 198, Art. 1327, 2012.

O duodeno está localizado ventralmente ao segmento jejuno-íleo e coloreto. Tem origem na face lateral direita do ventrículo, em gaviãozinho e na porção cranial da face ventrolateral direita em gavião-caboclo, através da alça descendente do duodeno. Esta segue caudolateralmente sob jejuno-íleo e contornando o ventrículo até encostar na porção caudal do coloreto, quando através de uma curva em direção cranial se une à porção ascendente. Equivale em média, a $12,84 \%$ do comprimento total dos representantes.

A alça ascendente do duodeno segue trajetória oposta, lateralmente à porção descendente, unindo-se ao segmento jejunoilíaco em uma curva caudal, ao nível da extremidade cranial da moela, dorsalmente à extremidade caudal do lobo hepático direito. Representa em média, $14,03 \%$ do comprimento total das aves.

Jejuno-íleo apresenta-se como um emaranhado de alças frouxamente unidas por mesentério e distribuídas no terço caudal da cavidade ventralmente aos lobos renais médio e caudal. Em gavião-caboclo situam-se predominantemente no antímero direito, ventralmente aos rins (exceto lobo renal cranial) e coloreto, e dorsalmente ao ventrículo. Equivale em média, a $71,86 \%$ do comprimento total dos representantes.

O gavião-caboclo possui um par de cecos delimitando intestino grosso e intestino delgado, os quais possuem formato cilíndrico, e maior diâmetro na base do que no ápice. Estão direcionados cranialmente, situados dorsalmente ao ventrículo. Os cecos direito e esquerdo equivalem respectivamente a 2,82\% e $2,51 \%$ do comprimento total da ave (Figura 03). Em gaviãozinho os cecos estão ausentes (Figura 04).

Em gaviãozinho, o coloreto tem início em um discreto estrangulamento intestinal, quando o conjunto de alças se desfaz ao nível da borda caudal da moela, à qual esse segmento une-se por mesentério e ventralmente ao lobo renal médio esquerdo. Segue ventralmente aos lobos renais médio e caudal esquerdos, 
SANTOS, A.L.Q. et al. Estudo anatomotopográfico do tubo digestório de Heterospizias meridionalis e Gampsonyx swainsonii (Accipitridae). PUBVET, Londrina, V. 6, N. 11, Ed. 198, Art. 1327, 2012.

até a cloaca, representando em média, $16,62 \%$ do comprimento total das aves (Figura 06).

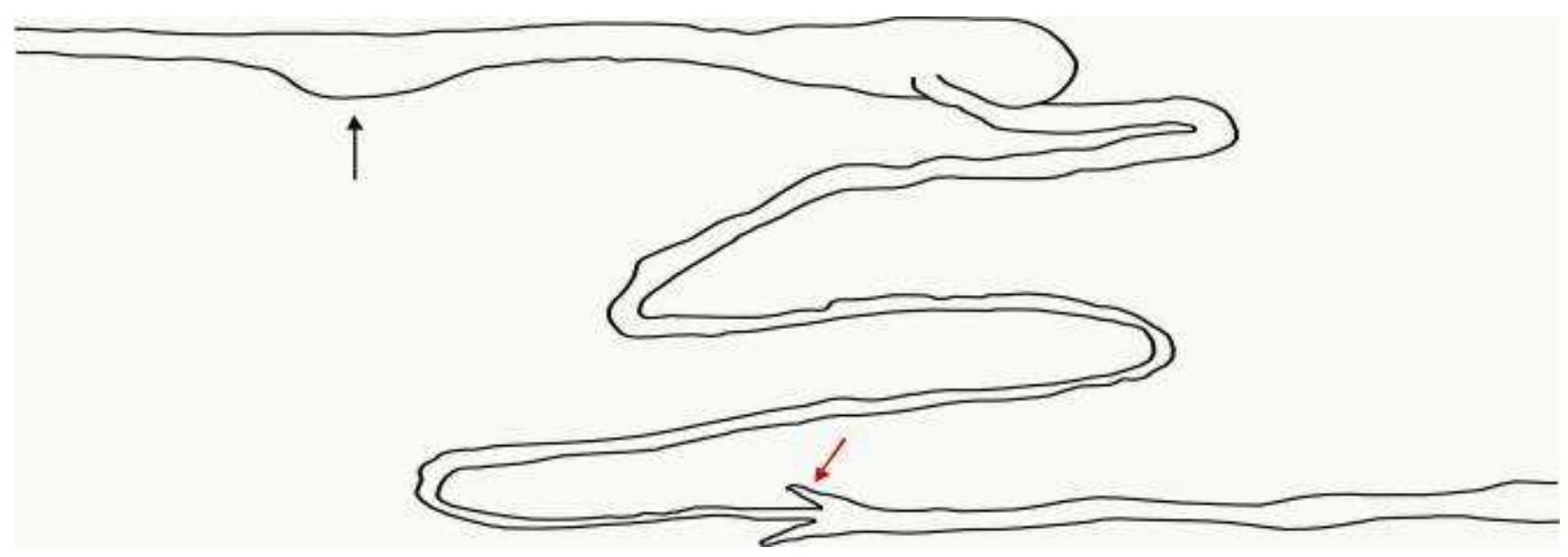

Figura 03: Representação esquemática do tubo digestório de gavião-caboclo (imaturo). Inglúvio (seta preta) e dois cecos de formato cilíndrico (setas vermelhas)

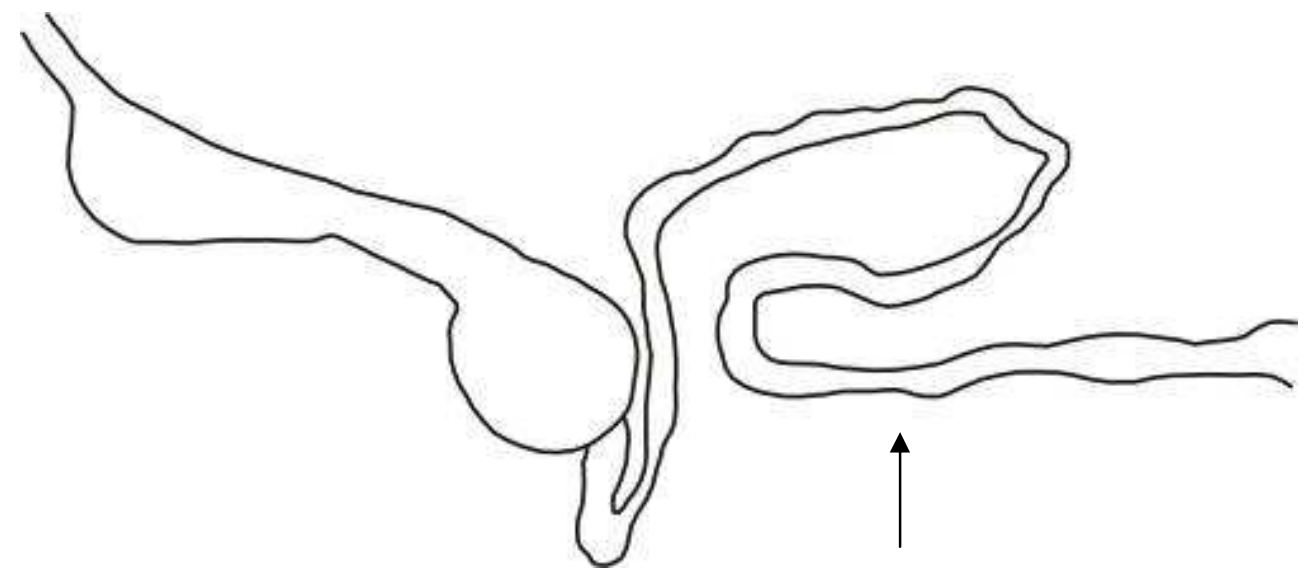

Figura 04: Representação esquemática do tubo digestório de gaviãozinho.

Transição entre intestino delgado e intestino grosso (seta preta). 
SANTOS, A.L.Q. et al. Estudo anatomotopográfico do tubo digestório de Heterospizias meridionalis e Gampsonyx swainsonii (Accipitridae). PUBVET, Londrina, V. 6, N. 11, Ed. 198, Art. 1327, 2012.

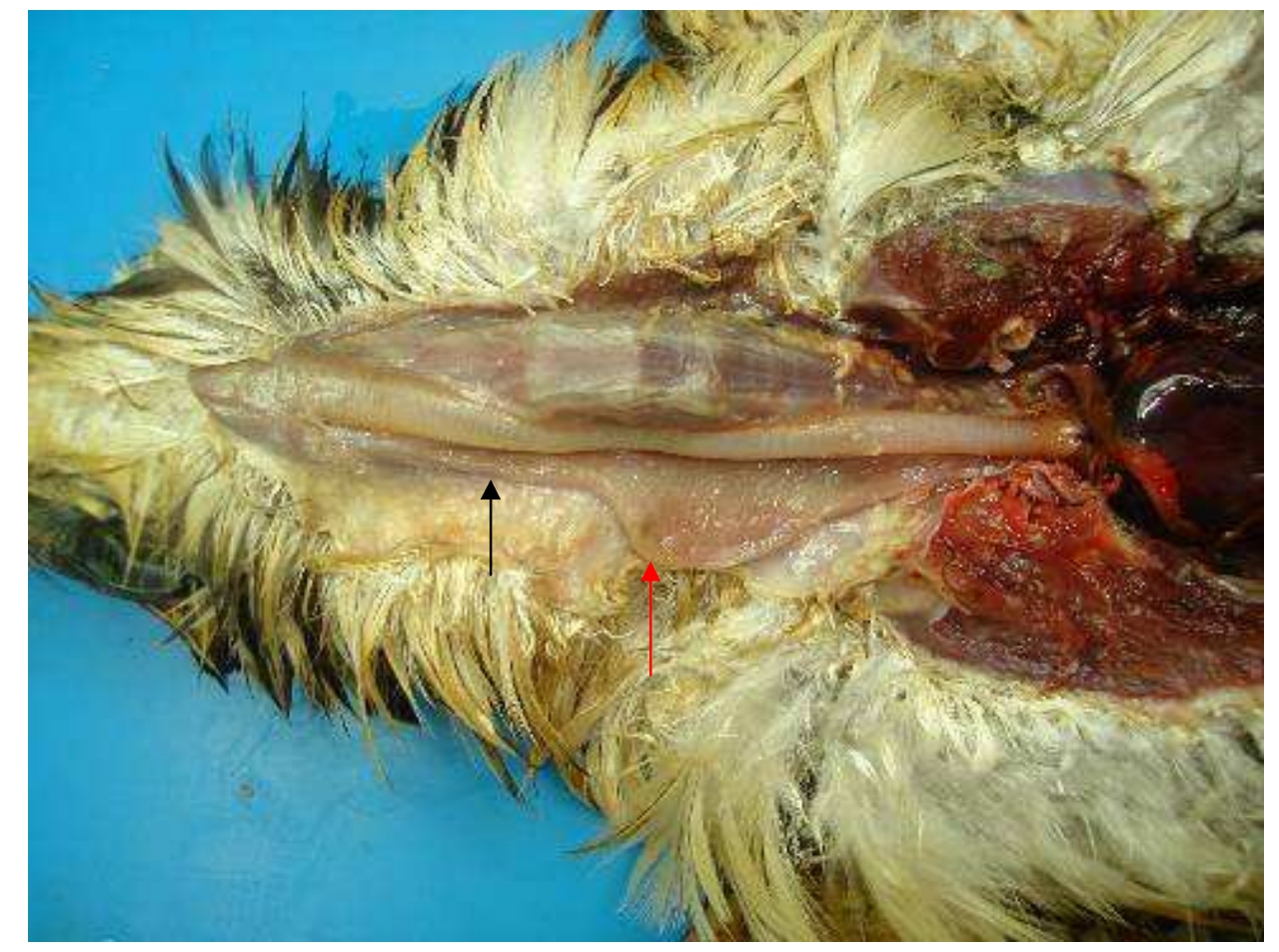

Figura 05: Esôfago cervical (seta preta) e inglúvio de Gavião-caboclo (seta vermelha) 
SANTOS, A.L.Q. et al. Estudo anatomotopográfico do tubo digestório de Heterospizias meridionalis e Gampsonyx swainsonii (Accipitridae). PUBVET, Londrina, V. 6, N. 11, Ed. 198, Art. 1327, 2012.

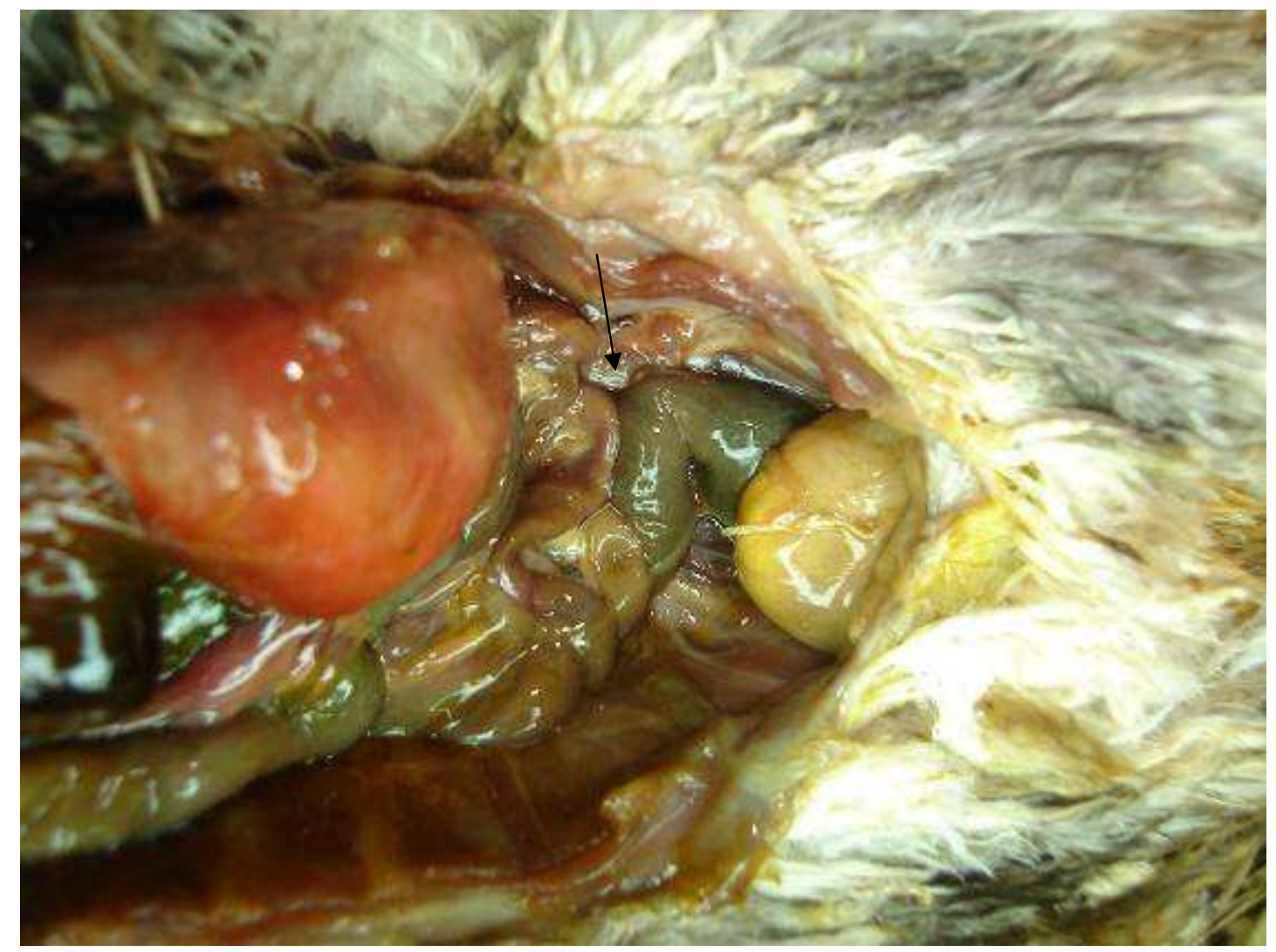

Figura 06: Coloreto (seta preta) em gavião-caboclo imaturo

\section{DISCUSSÃO}

Em nenhuma das ordens estudadas o esôfago cervical segue pela linha média do pescoço desviando-se caudalmente para o lado direito, como relatou Nickel, Schummer e Seiferle (1977) e Getty (1986) e nem posicionado ventralmente à traquéia (GETTY, 1986). A porção cervical tem início na face ventral do pescoço e logo no terço inicial desvia-se para o lado direito mantendo- 
SANTOS, A.L.Q. et al. Estudo anatomotopográfico do tubo digestório de Heterospizias meridionalis e Gampsonyx swainsonii (Accipitridae). PUBVET, Londrina, V. 6, N. 11, Ed. 198, Art. 1327, 2012.

se dorsalmente ou dorsolateralmente à traquéia, concordando com Dyce, Sack e Wensing, (1997).

Nas espécies estudadas ocorre a dilatação do esôfago cervical, o inglúvio, que está posicionado ventrolateralmente e cranialmente aos músculos peitorais, conforme relatou Getty (1986).

No trabalho de Nickel, Schummer e Seiferle (1977), o esôfago torácico estende-se dorsalmente á traquéia, entre a siringe e a superfície ventral do pulmão até a base do coração e superfície dorsal do fígado coincidindo com nossos resultados. Segundo Getty (1986), o esôfago torácico segue até a face medial do lobo hepático esquerdo, o que também foi observado em nosso experimento.

O estômago é dividido em proventrículo e ventrículo (NICKEL; SCHUMMER; SEIFERLE，1977, MACARI; FURLAN; NAKAGHI, 1994, BENNETT; DEEM, 1996), os quais são anatomicamente e fisiologicamente distintos (NICKEL; SCHUMMER; SEIFERLE, 1977).

O proventrículo é pequeno e situa-se cranialmente ao grande ventrículo, separado do mesmo por uma distinta constriç̧ão, o istmo, como descreveu Getty (1986), entretanto os dois estômagos apresentam pouca divisão entre si nos Accipitriformes, explicado pelo fato de que compõe-se por aves que se alimentam de grandes presas, nas quais esta característica anatômica está presente, conforme Bennett e Deem (1996). O estômago químico apresenta-se em posição paramediana esquerda, no terço médio da cavidade celomática, e não no quadrante inferior esquerdo como relatou Getty (1986). Observou-se uma relação do proventrículo com a face ventral do lobo hepático esquerdo, concordando com o citado por esse autor.

O estômago muscular possui formato arredondado, e bem desenvolvido justificando a observação feita por Duke (1996) e Bennett e Deem (1996), que afirmam ser o ventrículo altamente especializado em espécies que se nutrem de 
SANTOS, A.L.Q. et al. Estudo anatomotopográfico do tubo digestório de Heterospizias meridionalis e Gampsonyx swainsonii (Accipitridae). PUBVET, Londrina, V. 6, N. 11, Ed. 198, Art. 1327, 2012.

alimentos duros, e o diâmetro do seu eixo craniocaudal é maior que o dorsoventral, conforme relata Getty (1986). A face ventral do estômago muscular relaciona-se à superfície dorsal do lobo hepático esquerdo e em parte ao lóbulo direito como o descrito por Nickel, Schummer e Seiferle (1977).

O duodeno é o segmento mais ventral do intestino, se estende da porção cranial da face lateral direita do ventrículo e segue caudoventralmente em sua maior parte do lado direito e dorsalmente ao lobo hepático direito, apenas através de sua porção cranial, concordando em parte com a afirmação de Nickel, Schummer e Seiferle (1977) e Deem e Bennett (1996).

A união da porção descendente com a porção ascendente do duodeno ocorre ao nível do terço final do coloreto, ventralmente a este conforme já descrito por Getty (1986).

A alça ascendente do duodeno dispõe-se lateralmente à face direita da alça descendente do duodeno, mantendo contato com parte do segmento jejunoilíaco e parte do coloreto, relaciona-se à superfície dorsal do fígado, testículo direito ou ovário, de acordo com a citação de Nickel, Schummer e Seiferle (1977).

Nickel, Schummer e Seiferle (1977) relatam que a união entre o duodeno e jejuno-íleo ocorre ao nível do lobo renal cranial direito, igualmente ao observado em nossos achados.

O intestino delgado é dividido em três segmentos distintos, denominados duodeno, jejuno e íleo por Deem e Bennett (1996), Dyce, Sack e Wensing (1997), Getty (1986), Nickel, Schummer e Seiferle (1977), Andrade e outros (2004) e Borges e outros (2004). Ao contrário, este estudo considera apenas dois segmentos distintos denominados duodeno e jejuno-íleo, assim como Souza e outros (2005).

O segmento jejunoilíaco forma alças dispostas em "U", concordando com Deem e Bennett (1996). Estão dispostas uma sobre a outra, predominantemente no antímero direito da cavidade, como cita Dyce, Sack e Wensing (1997). 
SANTOS, A.L.Q. et al. Estudo anatomotopográfico do tubo digestório de Heterospizias meridionalis e Gampsonyx swainsonii (Accipitridae). PUBVET, Londrina, V. 6, N. 11, Ed. 198, Art. 1327, 2012.

É o segmento intestinal mais longo estudado, conforme o exposto por Nickel, Schummer e Seiferle (1977). Situa-se ventralmente aos rins e dorsalmente ao duodeno e estômago muscular concordando em parte com Getty (1986).

Observou-se que em Heterospizias meridionalis (imaturo), que o intestino grosso compreende um par de cecos e o cólon, como relata Nickel, Schummer e Seiferle (1977) e Dyce, Sack e Wensing (1997), porém, em Gampsonyx swainsonii constatou-se a ausência do par de cecos, apresentando somente o cólon. Em Caracara plancus, os cecos são estruturas vestigiais, demonstrando sua adaptação evolutiva à dieta praticada por rapinantes (FRANSO, et al., 2007).

Coloreto foi o termo utilizado para denominar o último segmento intestinal, diferindo de Nickel, Schummer e Seiferle (1977) que utiliza "cólon" e Getty (1986) e Schwarze (1980), que optaram por "reto". Estende-se da união ileocecal à cloaca, nas aves providas de ceco, assim como relata Deem e Bennett (1996) e localiza-se na parte dorsal do quadrante caudal esquerdo da cavidade celômica, como cita este mesmo autor.

\section{CONCLUSÕES}

- O tubo digestório apresenta poucas variações topográficas entre as duas espécies estudadas;

- Ausência de ceco no gaviãozinho (Gampsonyx swainsonii);

\section{REFERÊNCIAS}

ACCIOLY, A. M. R. Brasil 500 Pássaros. Local: Eletronorte - Centrais Elétricas do Norte do Brasil, 2000. Projeto.

ANDRADE, M. B.; SANTOS, A. L. Q.; CARVALHO, S. F. M.; BORGES, K. M.; OLEGÁRIO, M. M. M.; DIAS, E. A.; PEREIRA, R. V. V.; PEREIRA, P. C.; MIRANDA, R. L.; SILVA, C. B.; CASTRO, J. B.; ANDRADE, T. D.; COLICHINI, P. A. Descrição anatômica do tudo digestivo de Agapornis personata 
fischeri (PSITTACIDAE). In: ENCONTRO DE CIÊNCIAS AVÍCOLAS, 7., 2004, Uberlândia. Anais... Uberlândia: UFU. 2004, p. 13.

ANDRADE, M. B.; BORGES, K. M.; SANTOS, A. L. Q.; OLEGÁRIO, M. M. M.; SILVA, C. B.; PEREIRA, P. C.; DIAS, E. A.; PEREIRA, R. V. V.; DIAS, T. A.; CASTRO, J. B.; CARVALHO, S. F. M.; MIRANDA, R. L.; COLICHINI, P. A. Aspectos anatômicos do tubo digestivo de periquito-estrela (Aratinga aurea - GMELIN, 1788) (PSITTACIDAE). In: ENCONTRO DE CIÊNCIAS AVÍCOLAS, 7., 2004, Uberlândia. Anais... Uberlândia: UFU, 2004. p. 01.

BARTON, N. W. H.; HOUSTON, D. C. The incidence of intestinal parasites in british birds of prey. J. Raptor Res. v.35, n.1, p. 71-73, 2001.

BENNETT AVERY, R.; DEEM, S. L. O sistema gastrointestinal das aves: I. Compêndio de Educação Continuada - para o Médico Veterinário, Florida, v. 1, n. 1, p. 50-56, 1996.

BORGES, K. M.; ANDRADE, M. B.; OLEGÁRIO, M. M. M.; SILVA, C. B.; CASTRO, J. B.; CARVALHO, S. F. M.; SANTOS, A. L. Q. Descrição anatômica do tubo digestivo de frango-d'água-azul (Porphyrula martinica - LINNAEUS, 1776). In: SEMANA ACADÊMICA DA UNIVERSIDADE FEDERAL DE UBERLÂNDIA, 1., 2004, Uberlândia. Anais... Uberlândia: UFU, 2004. 1CD-Rom.

COMITÊ BRASILEIRO DE REGISTROS ORNITOLÓGICOS. Listas das aves do Brasil. 10a edição de 25/01/2011. Disponível em <http://www.cbro.org.br>. Acesso em: 12 dez. 2011.

DEEM, S. L.; BENNETT AVERY, R. O sistema gastrointestinal das Aves: II. Compêndio de Educação Continuada - para o Médico Veterinário, Florida, v. 1, n. 2, p. 118-123, 1996.

DYCE, K. M.; SACK, W. O.; WENSING, C. J. G. Tratado de anatomia veterinária. 2 ed. Rio de Janeiro: Guanabara Koogan, 1997. 663 p.

DUKE, G. E. Digestão nas aves. In: DUKES, H. H. Dukes/Fisiologia dos animais domésticos. 11 ed. Rio de Janeiro: Guanabara Koogan, 1996. p. 390-397.

FLÔRES, M. L. et al. Surto de megabacteriose em canários-belgas (Serinus canária) em um criatório no estado do Rio Grande do Sul: relato de caso. Clínica Veterinária, São Paulo, v. 10, n. 54, p. 24-26, jan/fev. 2005.

FRANZO, V. S.; ARTONI, S. M. B.; VULCANI, V. A. S.; SAGULA, A.; MORAES, C. Análise biométrica do intestino do carcará (Polyborus plancus, Miller 1777). Biotemas, v. 20, n. 2, p. 83$88,2007$.

JUNIPER, T.; PAN, M. Parrots - a guide to parrots of the world. New Haven: Yale University Press, 1998. $584 \mathrm{p}$.

LEMOS, M. et al. Salmonella em aves silvestres no Jardim Zoológico do Rio de Janeiro, RJ. Revista Brasileira de Ciência Veterinária, Niterói, v. 6, n. 1, p. 40-43, jan/abr. 1999.

MAPELI, E. B. Sstemática e parâmetros epidemiológicos de helmintos parasitos de jaós (Crypturellus undulatus), no estado do Mato Grosso do Sul (Pantanal de Paiaguás), e de codornas (Nothura maculosa) e nambuzinhos (Crypturellus parvirostris) no estado de São Paulo, 2003. 84 f. Dissertação (Doutorado) - Faculdade de Ciências Agrárias e Veterinárias, Universidade Estadual Paulista, Jaboticabal, 2003. 
MARÇAL Jr., O. M.; FRANCHIN, A. G. Aves, do latim Avis. In: DEL-CLARO, K.; PREZOTO, F. As distintas faces do comportamento animal. Jundiaí: Livraria Conceito, 2003. p. 105-119.

PETERSON, R. T. et.al. As aves. Rio de Janeiro: J. Olympio, 1971. 208 p.

POUGH, F. H.; HEISER, J. B.; McFARLAND, W. N. Características das aves: especializações para o vôo. In: A vida dos vertebrados. 2 ed. São Paulo: Atheneu, 1999. cap. 17, p. 521-552.

SCHWARZE, E. Compêndio de anatomia veterinária - anatomia de las aves. Zaragoza: Acribia, 1980. 212 p.

SMITH, B. J.; SMITH, S. A. Radiology. In: ALTMAN, R. B. et al. Avian medicine and surgery. Philadelphia: Saunders Company, p. 170-199.

SOUZA, A. G.; BORGES, K. M.; OLEGÁRIO, M. M. M.; ANDRADE, M. B.; PEREIRA, P. C.; SANTOS, A. L. Q.; VIEIRA, L. G. Descrição anatômica do tudo digestivo de periquito- australiano-azul (Melopsittacus undulatus). (FRINGILLIDAE). In: ENCONTRO SOBRE ANIMAIS SELVAGENS MANEJO E CONSERVAÇÃO, 3., 2005, Uberlândia. Resumos... Uberlândia: Universidade Federal de Uberlândia, 2005.

SOUZA, D. Todas as aves do Brasil. Guia de campo para identificação. Feira de Santana: Dall, 1998. 239 p. 